\title{
On idiomaticity in English and Arabic: A cross - linguistic study
}

\author{
Ali Yunis Aldahesh \\ The University of Sydney, Austrialia. \\ Accepted 13 March, 2013
}

\begin{abstract}
The phenomenon of idiomaticity constitutes a common factor in all living languages and its appreciation is considered the cornerstone of learning and mastering any given language. The semantic, syntactic and pragmatic complexity of idiomatic expressions, in any language, poses a great deal of challenges to learners of that language, and also to translators translating from and/or into it. The main purpose of this paper is to throw some light on this phenomenon in a contrastive analysis framework in an attempt to perceive the ways by which English and Arabic function in relation to idiomaticity. This is done by using the two principal steps of contrastive analysis procedure proposed by James (1980), that is description and comparison respectively. Hence, the core properties of this phenomenon are described in both English and Arabic languages, and then a comparison is conducted to highlight the matches and mismatches between the two languages in this respect. Other researchers may well take these nuances as a platform from which they explore some strategies of teaching, learning and translating idiomatic expressions from/into both languages. This paper concludes with proposing a number of recommendations to be taken by teachers and translators when tackling such a demanding phenomenon.
\end{abstract}

Key words: Idiomatic Expressions, Culture-specific Idioms, Phrasal Verbs, Proverbs, Contrastive Analysis.

\section{IDIOMATICITY IN ENGLISH}

Idioms have been defined in various ways by English linguists, grammarians, lexicographers and pedagogues. To take just a few of these definitions, an idiom may be referred to as "[a] fixed expression whose meaning is not guessable from the meaning of its parts" (Trask, 2000, p. 67). Fraser (1976) considers an idiom as "a single constituent or series of constituents, whose semantic interpretation is independent of the formatives which compose it" (p. v). In the Longman Dictionary of Applied Linguistics, Richards et al. (1985) define an idiom as "an expression which functions as a single unit and whose meaning cannot be worked out from its separate parts" (p. 134). Idioms, according to Bolinger (1975), are "groups of words with set meanings that cannot be calculated by adding up the separate meanings of the parts" (as cited in Lattey, 1986, p. 219). Further, Baker
(1992) rightly points out that idioms "are frozen patterns of language which allow little or no variation in form and [...] often carry meanings which cannot be deduced from their individual components" (p. 63). Thus, with idioms a user cannot normally change the order of the words in them, delete a word from them, replace a word with another, or change their grammatical structure unless he or she is intentionally making a joke or trying a play on words (Baker, 1992). Therefore, Lattey (1986) points out that "as far as the form of idioms is concerned, we have groups of words, and in terms of meanings, we can say that we are dealing with new, not readily apparent meanings when we confront idioms" (p. 219).

In his attempt to coin a comprehensive definition, Ghazala (2003) defines idioms as "special, metaphorical, fixed phrases whose meanings and forms are not 
negotiable" (p. 204). Additionally, he sums up the main features of idioms in five points as follows:

1. Idioms are all in all metaphorical and cannot be understood directly.

2. They should not be taken literally; in the sense that their meanings are not the outcome of the individual meanings of their constituent words taken collectively.

3. Their syntactic form is usually fixed and cannot be changed or described as ungrammatical [...].

4. Their meanings are also invariable.

5. [...] They are mainly cultural and informal (p. 204).

Idioms, though, are considered as "vivid, verbal images which add life and verve to speech and writing. Without them language would be very bland and unexciting" (John and Smithback, 1991, preface). Hence, their importance in any language "cannot be doubted [in view of the fact that their] ubiquity makes them anything but a marginal phenomenon" (Wallace, 1968, p. 112).

Some of the fairly common examples include: let the cat out of the bag (meaning: reveal a secret يُشي سراً), a fish out of water (meaning: a person struggling in an unfamiliar environment كسمكة خارج الماء), kick the bucket (meaning: die يموت، يلفظ آخر أنفاسه) (Trask, 2000), and he washed his hands of the matter (meaning: he refused to have anything more to do with the matter نفض يديه، رفض (تحمّل المسؤولية) (Richards et al., 1985).

A great deal of attempts has been made by English scholars to classify idiomatic expressions. As a result, they have been categorized in many different ways, being: 1) according to their 'grammatical type' such as verb-adverb idioms, or idioms that function like a particular part of speech; 2) according to the 'concept or emotion portrayed' for instance, the idiom tell someone a tall tale would be categorized under LIE; and 3) according to the 'image' it conveys, that is, the picture drawn by the idiom, for example, a category BODY PARTS would include she lost her head (Lattey, 1986).

It must be stressed here that idioms involve many aspects of the English language. They may occur in such forms as: slang, proverbs, allusions, similes, dead metaphors, social formulate, and collocations (Fernando, 1996). Furthermore, Ghazala (2003) classifies idioms into five main types, being:

1. Full / pure idioms;

2. Semi-idioms;

3. Proverbs, popular sayings and semi-proverbial expressions;

4. Phrasal verbs;

5. Metaphorical catchphrases and popular expressions (p. 208).

What has to be confirmed at this stage is that phrasal verbs (verb + particle, e.g. take off, give up etc.) constitute an integral part of English idiomatic expressions
(Aldahesh, 2009). They have been classified as one category of English idiomatic expressions by many researchers other than the above mentioned by Lattey (1986) and Ghazala (2003) (Spears, 1987; Alexander, 1984: Urdang, 1979 as cited in Bataineh and Bataineh, 2002, p. 40).

In his book The Verb-Particle Combination in English, Fraser (1976) emphasizes that "[p]ractically every grammarian of English has noted and commented about idioms in general. More specifically, almost all have noted the regularity with which certain adverbials (particles) cooccur with certain verbs" (p. 63).

Phrasal verbs' elements sacrifice their individual meanings and by the act of combination assume a new meaning. Examples include, bear out (meaning: corroborate), come by (meaning: acquire), get at (meaning: reach), make out (meaning: understand), own up (meaning: confess), and put out (meaning: extinguish) (Kennedy, 1967). It is quite evident that in such idiomatic phrasal verbs, the meanings of the separate parts tell us little or nothing about the meaning of the whole. For instance, one may be quite familiar with the meanings of the items pick and up as individual words, but such familiarity does not help in understanding the idiomatic meaning of the phrasal verb pick up in such sentence as: Business is picking up (Turton and Manser, 1985).

Along these lines, Kharma and Hajjaj (1989) assert that "[a]n idiom is a fixed phrase [...] whose meaning cannot be predicted from a knowledge of the meaning of the individual words. An idiom in this respect is similar to a phrasal verb" (p. 72).

It is interesting to note that Barkema (1996) believes that the definition of 'idioms' as 'lexicalised expressions with idiosyncratic meanings" has been the standard definition employed by the majority of linguists for more than a century. Later definitions, Barkema explains, "boil down to the same two things: (a) idioms are expressions which contain at least two lexical items and (b) the meaning of an idiom is not the combinatorial result of the meanings of the lexical items in the expression" (p. 127).

Idioms, however, are not necessarily combinations of words. Some of them are one-item phrases, e.g., cheers (when toasting) and speaking (telephonese) (Warren, 2005).

This essential point has been outlined by Barkema (1996) in the following way:

"Although practically all definitions of idioms require them to be 'lexically complex', an exception to this rule is Charles Hockett's definition (1958:172), which implies as Hockett admits- that words and morphemes can be idioms too and that all forms which are not idioms themselves, contain them [...] In this sense idioms are the basic semantic units of a language, no matter whether they are morphemes, words, phrases, clauses or sentences (p. 127)". 
Another essential point to be added here is that some idioms are characterised by violation of the truth conditions and our understanding of reality (Baker, 1992; Homeidi, 2004). In their endeavour to illustrate this point Baker (1992) and Homeidi (2004) provided the following examples:

It's raining cats and dogs, which can be translated into Arabic as: إنها تمطر كأفواه القرب

Storm in a tea cup, which can be translated into Arabic jوبعة في فنجان as

Throw caution to the winds, which can be translated into لم يعد يكترث لأي شيء : Arabic as

Jump down someone's throat, which can be translated into Arabic as: يوبخ بعنف

Other idioms are characterised by being grammatically illformed, that is, they violate the English grammatical rules. This type is exemplified by Baker (1992) and Homeidi (2004) in what follows:

By and large, which can be translated into Arabic as: على العموم

Trip the light fantastic, which can be translated into Arabic as: يُمضي ليلة حمر fras

Blow someone to kingdom come, which can be translated into Arabic as: يمسح من على وجه الأرض

The world and his friend, which can be translated into Arabic as: كل إنسان

In addition, idioms may start with "like" to form "simile-like structures" (Baker, 1992). Some examples are:

Like a bat out of hell, which can be translated into Arabic as: الانسحاب بصورة كاملة

Like water off a duck's back, which can be translated into Arabic as: دون أي أثر (كأثر الماء على ذيل البط)

Idiomaticity, however, is, as Ghazala (2003) puts it, the idioms' "most special component [which constitutes] their metaphorical aspect" (p. 204), or "the heart of the matter of any idiomatic expression" (p. 208), and "the gist of any idiomatic phrase" (p. 209). Idiomaticity, in the words of Weinreich (1969), is "important for this reason, if for no other, that there is so much of it in every language" (as cited in Fernando, 1996, p. 1). Lastly, it is, according to Palmer (1974), "a lexical feature [i.e.], something to be dealt with in the lexicon or dictionary rather than the grammar" (p. 213).

Inspired by Pawley and Syder (1983), and Fillmore et al.
(1988), Warren (2005) offers the following two definitions of idiomaticity:

(i) Nativelike selection of expression;

(ii) That which one has to know over and above rules and words (p. 35).

In an attempt to account for the term 'idiomatic', AbuSsaydeh (2004) states that this term is used in one of three senses, which are:

a. As a property of discourse; a piece of discourse is described as idiomatic if it sounds "natural" or nativelike. Thus, a foreign learner's speech or text will be "idiomatic" if it resembles that produced by the native speaker;

b. Lexical combinations which occur as grammatical units in the language like phrasal verbs. [...];

c. A general term equivalent to multi-word units or phrasal expressions. In this sense, the following expressions would be "idiomatic": at last [أخيرا], drop by [يقوم بزيارة قصيرة مفاجئُ] (p. 114).

Kavka and Zybert (2004) usefully point out that the terms idiomatology, idiomaticity, idiomatic and phraseology are used to refer to one and the same area, that is, idiomaticity, and "[...] idiomatic expressions are based on semantic rather than lexical grounds" (p. 55). They also indicate that "[t]eachers, as practitioners, may feel fairly satisfied, though: what they generally imagine is a list of 'useful phrases' for their pupils to learn by heart. They may not realize the fact that idiomatic expressions are based on semantic rather than lexical grounds..." (pp. 5455). Yet, understanding idioms and using them properly entails a degree of proficiency which is hard for the nonnative speaker of a given language to acquire (Turton and Manser, 1985). Therefore, Wallace (1981) observes that "[w]hen it comes to understanding English it is these expressions which cause most difficulty to the foreign learner" (p. 5).

Along these lines, Wiktorsson (2003) investigated how Swedish learners of English at different levels of proficiency master idiomaticity. She indicates that the mastery of idiomaticity is one of the most difficult tasks in the learning of a foreign language. In addition, Wiktorsson points out that even advanced learners constantly fail to reach a native-like level of idiomaticity.

\section{ENGLISH LANGUAGE AND CULTURE-SPECIFIC IDIOMS}

Idioms, like any other aspect of a given language, are of two types in terms of their meanings: universal and language or culture-specific. That is, they may have universal meanings which are common to many languages, or specific meanings which are, due to linguistic and/or 
cultural restrictions, confined to the speakers of that particular language and cannot be easily understood by speakers of other languages. This point constitutes the crux of the definitions given to 'idiom' by the Concise Oxford Dictionary of Current English (Sykes, 1982). In defining the term, this dictionary focuses on the issue of 'peculiarity'. It provides the following definitions: "language of a people or country; specific character of this; form of expression peculiar to a language or person, peculiarity of phraseology approved by usage through having meaning not deducible from those of the separate words [...]" (p. 495).

Hence, when linguists, lexicographers and pedagogues talk about mastering the use of idiomatic expressions by a language learner as an indicator of language proficiency they mean knowing the language and culture specificity of those expressions. It is this knowledge which makes learners sound as if they are native or native-like speakers. And that is why scholars who studied the notion of idiomaticity have addressed the questions of 'frequency' and 'acceptability by native speakers' as measurements of judging idiomaticity. Kavka and Zybert (2004), for instance, point out that:

"[...] Understanding the term [idiomaticity] in its broader sense, it can be said that an expression is 'idiomatic' (or, has 'proper idiomaticity' if it is judged intuitively by native speakers as usual, natural, and commonly acceptable. In this respect of fairly acceptable, and concise, definitions of 'idiomaticity' will be one that takes it as a function of familiarity and frequency of use, (this wording is after Sonomura, 1996 p.55) [emphasis in original]".

Likewise, Mahmoud (2002) makes the point that "[idioms'] frequent, spontaneous and appropriate daily use is an indication of native or near-native command of the language" (p. 1).

English language and culture-specific idioms can be illustrated by the English saying to carry coals to Newcastle كناقل التمر إلى هجر. More examples (taken from Mowafi, 1985, p. 156) are:

Before you can say Jack Robinson (meaning: في لمح البصر (Rutremely quickly)

Jack is as good as his master (meaning: men with power are not necessarily better than those لا أحد أحسن من أحد، الناس سواسية (mithout power)

Jack of all trades (meaning: one capable of undertaking a verity of jobs) كثير الكارات قليل البارات:عا (2) (ع)

Kharma and Hajjaj (1989) make the point that the great majority of English idioms are language and culturespecific idioms especially when they are parts of proverbs. They provide the following examples:

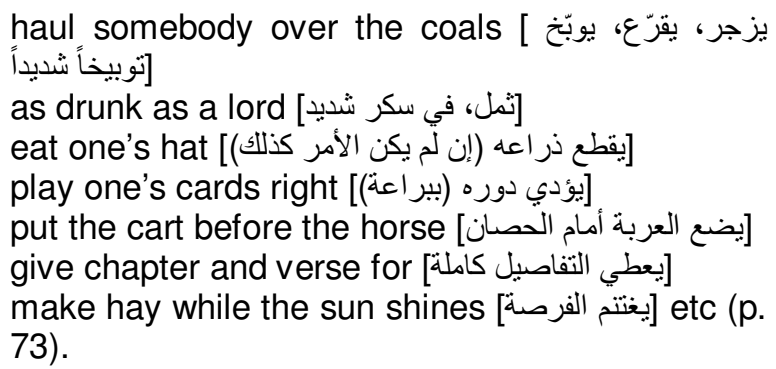

To sum up so far, idiomaticity has been understood by scholars of the English language as the essence of idiomatic English expressions whose meanings are in no way transparent and cannot be inferred from the meanings of their individual parts. Idioms are also characterised as being language and culture-specific, such a characteristic adds more to their traditional syntactic and semantic complexity.

\section{IDIOMATICITY IN ARABIC}

The phenomenon of idiomaticity and idiomatic expressions in the Arabic language has been exclusively tackled in the Arabic rhetoric (علم البيان) by many ancient and modern Arabic writers such as Al-jaaHiZ (died 255 A.H.) in his book البيان والتيبين (rhetoric and clarification) [my translation], Al-jurjaanii (died 471 A.H.) in his books أسرار دلائل الإعجاز (secrets of rhetoric) [my translation] and البلاغة (indications of inimitability) [my translation], and Alzamakhsharii (died 538 A.H.) in his books أساس البلاغة (foundation of rhetoric) [my translation] and الكثّاف (the explorer) [my translation] among others.

Rhetoric (علم البيان) is defined by Arabic linguists as "a science by which the stating of a single meaning in different ways, with a clear indication to it [the meaning], is known" [my translation] (Shakkour, 1992, p. 64). This science discusses four rhetorical styles: 1) المجاز (figurative expression), which means: using a word in other than its original meaning owing to a relation (other than the similarity relation) between the two meanings with a presumption that the original meaning is not intended (Sayyd Ahmad, 1993) [my translation]. To take one example: انهمر الثنتاء (The winter [sic] poured down) (Shakkour, 1992) [my translation]. In this example the original meaning of winter (الثناء) is not intended. What is meant by winter here is the rain due to the fact that the rain pours down only in winter in the Arab world; 2) التثبيه (simile), which is, following Shakkour (1992, p. 65), "[a]n indication of the sharing of one meaning by two things" [my translation]. For instance: لبنان كالجنة في الجمال (Lebanon is like Paradise in beauty) [my translation]. In this sentence Lebanon and Paradise share one meaning, that is, beauty (p. 65); 3) الاستعارة (metaphor), which means: using a word in a meaning which is not its original one, owing to a similarity relation between the two meanings with a presumption that the original meaning is not 
intended (Sayyd Ahmad, 1993) [my translation]. For example:ضنك المصباح منيراً (The shining light smiled) (p. 125) [my translation]. In this example the original meaning of light is not intended, it is rather borrowed here to refer to a handsome person due to the similarity between the light and the handsome person, i.e. both are shining; and 4) الكناية (antonomasia), which means: any word that expresses a meaning which can be perceived literally and metaphorically at the same time (Shakkour, 1992) [my translation]. For example: يد حسن مبسوطة (Hassan's hand is outstretched) (Sayyd Ahmad, 1993) [my translation]. In this example it is possible to perceive the meaning of outstretched literally, that is, it is not grasped, or metaphorically, i.e. he is a generous person.

At this point, it is insightful to say that idiomaticity is the common factor among all the abovementioned examples. Such idiomaticity is represented by the lack of transparency in the meaning of each sentence if taken literally. In other words, the intended meaning of each example cannot be deduced from the total sum of the meanings of its words.

This having been said, people in the Arab world use idiomatic expressions for two reasons, according to Abu Sa'ad (1987 as cited in Bataineh and Bataineh, 2002), they are:

1) to beautify their language and distinguish it through such a stylistic phenomenon [...and] 2) to avoid mentioning a word that may cause embarrassment or annoyance (p. 47).

It is necessary to point out that the structural and semantic characteristics of Arabic idioms may be outlined as follows:

1. Idioms come in the following structural patterns:

a. A sentence which consists of two or more words; Example: to put the cart before the horse [ يضع العربة أمام الحصان]

b. Genitive constructions whose individual meanings are familiar, while the result of their combination is unfamiliar; Example: Noah's ark [سفينة نوح] 'something that gathers many objects or species', the patience of Job [صبر أيوب]] 'real patience and tolerance'

c. Individual idiomatic words; Example: He is an ear [ هو [أن ] 'He tells of what he hears without thinking'.

2. They are influenced by certain linguistic phenomena such as:

a. Synonymy [التر ادف], where different structures express the same meaning;

b. Homonymy [التباين], where one structure expresses different meanings; and

c. Antonymy [التضاد], where one structure expresses opposite meanings.

3. Idioms are related to proverbs and, thus, the more common the proverb the greater its chance of being an idiom.
4. Idioms derive their figures from the environment, [and] Arabic, like English, is full of idiomatic expressions. Yet, there are more of them in Arabic dialects than in Modern Standard Arabic. [...] Many of the Arabic idioms are easy to understand because their meanings are not that far from the sum total of their respective components. But others, just as in English, are difficult to understand, especially for non-native speakers of Arabic, simply because their meanings are far from the sum of their components (Abu Sa'ad, 1987 as cited in Bataineh and Bataineh, 2002, pp. 47-48).

Along these lines, Awwad (1990) indicates that what is said about English idioms regarding their semantic and syntactic restrictions also applies to Arabic idioms. He gives the following example: عاد بخفي حنين (he returned empty-handed) (literally: he returned with the slippers of Hunain) where we cannot substitute وصل (he arrived) or سار (he walked) for عاد (he returned) and keep the idiomaticity of the expression (p. 58).

Moreover, in his attempt to further compare English idioms with their Arabic counterparts, Awwad (1990) makes the point that English idioms can be lexemic as in (hammer and tong), phraseological as in (to fly off the handle) and proverbial as in (don't wash your dirty linen in public). The lexemic idioms, however, can be verbal (verb + particle) as in (break in), nominal as in (hot dog), adjectival as in (pepper and salt), and adverbial as in (hammer and tong). By the same token, Arabic idioms can be lexemic as in شحم ونار (literally: fat and fire, meaning: completely opposites), phraseological as in على (literally: on my eye / head, meaning: with pleasure), and proverbial as in من سار على الدرب وصل (literally: he who walks on the road will get there, meaning: he who takes the first step will eventually achieve his aims). Like English, Arabic lexemic idioms can be verbal, nominal, adjectival, and adverbial (p. 58). Yet, "Arabic verbal lexemic idioms do not occur with particles" (p. 58). Therefore, the Arabic equivalent for (he broke into the house) is دخل البيت عنوة or (meaning: he entered the house by force) (p. 58). Hence "Arabic verbal lexemic idioms are made up of either the verb alone or the verb followed by an adverbial nominal" ( $p$. 58).

Similarly, Kharma and Hajjaj (1989) indicate that "Arabic is no different from English in this respect, and is full of idiomatic expressions. The only difference is that there are more of them in the various Arabic dialects than in Modern Standard Arabic" (p. 74).

In terms of difficulty, Kharma and Hajjaj (1989) divide Arabic idioms into three categories. The first category are those Arabic idioms that are easy to understand because the meaning of the whole phrase is not very far from the total sum of its components. They are as follows:

centre forward (in football)

from the bottom of the heart 
مانل للعيان visible

inner voice

to imitate someone

to die, pass away (p. 74).

The second category are those Arabic idioms that, like most English idioms, are difficult to understand especially for the non-native speaker of Arabic. Examples are as follows:

with great difficulty

to breathe a sigh of relief

with heart and soul

give someone the cold shoulder

by heart

give free reign to (pp. 74-75).

The third category are those Arabic idioms that are very difficult to understand because they are very culturespecific. They provide the following examples:

على نفسها جنت براقش it was her own fault (that she hurt herself)

the married couple are very suited to each other

you cannot always have what you want

it expired or become obsolete

دارت رحى الحرب war broke out (p. 75).

It is worth noting that in their monolingual Arabic-Arabic dictionary المعجم السياقي للتعبيرات الاصطلاحية (The Contextual Dictionary of Idiomatic Expressions) [My translation] Siinii et al. (1996) arranged more than 2000 Arabic idiomatic expressions, collected from a wide range of ancient and modern Arabic literature, and representing all aspects of this phenomenon in the Arabic language.

\section{ARABIC LANGUAGE AND CULTURE-SPECIFIC IDIOMS}

Having elaborated on the core properties of Arabic idioms, let us now investigate their specificity in terms of Arabic language and culture. The abovementioned five Arabic idiomatic expressions given by Kharma and Hajjaj (1989), described by them as "very difficult to understand", constitute obvious instances to illustrate the type of idioms which are Arabic language and culturespecific. They are categorised as such because each of them is culture bound and has a social, political or historical narrative behind it. Therefore, the intended meaning of each expression cannot be deduced without knowing such a narrative and the moral it may impart.

Like English, the majority of Arabic idioms are language and culture-specific due to the fact that they are parts of proverbs. It is worth mentioning that it is this type of idiomaticity which poses the most difficulty to learners of Arabic and to translators from and into it. Conveying these idioms in English may cause comprehension problems if the listener or reader is not familiar with Arabic language and culture (Mahmoud, 2002).

In an empirical study conducted by Mahmoud (2002) to investigate the interlingual transfer of idiomatic expressions performed by students in classroom EFL learning situations, he detected the following Arabic languagespecific idioms in the written assignments examined:

- he paid in spite of his nose [رغ أنفه]]

- it was Osman's shirt [قيص عثمان]

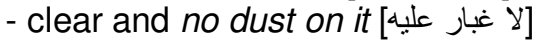

- tries to put ash in the eyes [ذر الرماد في العيون] [لاليار]

- as if birds on their heads [كأن على رؤوسهم الطيرن]

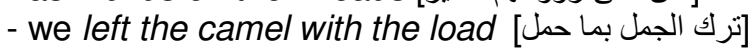

Such a literal translation of the Arabic language and culture-specific idioms into English is an absolute distortion. The same will happen if the English language and culture-specific idioms are translated literally into Arabic without paying attention to their linguistic and cultural restrictions.

\section{CONCLUSION AND RECOMMONDATIONS}

In summary, six fruitful insights can be arrived at as to the notion of idiomaticity in both Arabic and English. They are: 1) generally speaking, both languages rely on idiomatic expressions in all aspects of their spoken and written modes; 2) idiomatic expressions in both languages are of a special nature and subject to syntactic and semantic restrictions; 3 ) they are, in both languages, rather language and culture-specific and their meanings are far from the sum of the meanings of their individual components; 4) their semantic and syntactic complexities require a high proficiency level on the part of non-native speakers to be able to understand and produce them properly; and 5) unlike English which allows idioms to be grammatically ill-formed, Arabic idioms are perfectly grammatical; and 6) unlike English which gives a clear prominence to phrasal verbs as one of the most important types of idiomatic expressions, Arabic does not categorize them as such. This is basically because they do not represent such a category in the Arabic language. With the abovementioned findings in mind, teachers of English as a second or foreign language are best recommended to take these common factors into their consideration when teaching idioms to non-native speakers. For them to be able to allow their students to grasp the intended meaning of idiomatic expressions from the contexts in which they are used, they need to have a very good command of idiomatic English expressions, and use them frequently enough in the classroom. They also have to avoid providing their students with, as 
Kavka and Zybert (2004) terms it, a list of 'useful phrases'. They instead need to take into their account that each idiomatic expression forms a solid and fixed unit of meaning, which cannot be taken out of its linguistic and extra-linguistic context. Moving onto translation, the difficulty of achieving a native speakers' competence in using idiomatic expressions was the main reason behind instructing translators to work only into their mother tongues (Baker, 1992, p. 64). Yet, even when working into their mother tongues translators are best advised to avoid targeting the direct, literal meanings of idiomatic English expressions and opt for appreciating their figurative, metaphorical and contextual meanings. To do so, they ought to be, to a certain extent, familiar with the idiomatic behaviour of these expressions which are characterized by their lack of transparency mainly due to their language and culture-specific nature.

\section{REFERENCES}

Abu-Ssaydeh A (2004). Translation of English Idioms into Arabic, Babel, 50(2):114-131.

Aldahesh AY (2009). Translating Idiomatic English Phrasal Verbs into English: A Contrastive Linguistic Study. VDM: Germany.

Awwad M (1990). Equivalence and Translatability of English and Arabic Idioms. Papers and Studies in Contrastive Linguistics (26):57-67.

Baker M (1992). In Other Words: A coursebook on translation. London and New York: Routledge.

Barkema H (1996). Idiomaticity and Terminology: A Multi-Dimensional Descriptive Model, Studia Linguistica 50(2):125-160.

Bataineh RF, Bataineh RF (2002). The Difficulties Jordanian Graduate Learners of English as a Second language Face When Translating English Idioms into Arabic. RASK 16:33-83.

Fernando C (1996). Idioms and Idiomaticity. Oxford: Oxford University Press.

Fraser B (1976). The Verb-Particle Combination in English. New York, San Francisco and London: Academic Press.

Ghazala H (2003). Idiomaticity Between Evasion and Invasion in Translation: Stylistic, Aesthetic and connotative Considerations. Babel 49(3):203-227.

Homeidi MA (2004). Arabic Translation across Cultures. Babel 50(1):1327.

James C (1980). Contrastive Analysis. London: Longman.
John, Smithback CY (1991). Fun with Idioms. Singapore: Federal Publication.

Kavka S, Zybert J (2004). Glimpses on the history of Idiomaticity Issues, SASE J. Theor Linguist 1(1):54-66.

Kennedy AG (1967). The Modern English Verb-Adverb Combination. AMS Press Inc: New York.

Kharma N, Hajjaj A (1989). Errors in English Among Arabic Speakers: Analysis and Remedy. London: Longman

Lattey E (1986). Pragmatic Classification of Idioms as an Aid for the Language Learning. IRAL 24(3):217-233.

Mahmoud A (2002). Interlingual Transfer of Idioms by Arab Learners of English. Internet TESL J. 8(12).

Mowafi MI (1985). A Dictionary of English idioms English-Arabic. Beirut: Librairie Du Liban.

Palmer FR (1974). The English Verb (Second Ed.). London: Longman.

Richards J, Platt J, Weber H (1985). Longman Dictionary of Applied Linguistics, Longman Group UK Limited. England.

Sayyd Ahmad RA (1993). Fannu al-kitaabah. Beirut (in Arabic): Daar albayaan al-3arabii.

Shakkour J (1992). Kitaab al-bayaan (in Arabic). Beirut: Daar al-fikr allubnanii.

Siinii M, Hussein M, Al-doush SA (1996). Al-mu3jam al-syaaqii lilta3biiraat al-?iSTilaaHyyah (in Arabic). Beirut: maktabat lubnan nashiroun.

Sykes JB (1982). Concise Oxford Dictionary of Current English. London: Oxford University Press.

Trask RL (2000). Dictionary of English Grammar. London: Penguin Group.

Turton N, Manser M (1985). The Student's Dictionary of Phrasal Verbs. London and Basingstoke: Macmillan.

Wallace LC (1968). Idiomaticity as an Anomaly in the Chomskyan Paradigm. Foundations of Language (4):109-127.

Wallace MJ (1981). Dictionary of English Idioms. Glasgow and London: Collins.

Warren B (2005). A Model of Idiomaticity. Nord. J. English Studies, $4(1): 35-54$

Wiktorsson M (2003). Learning Idiomaticity: A Corpus-Based Study of Idiomatic Expressions in Learners' Written Production. Land Studies in English 105. Stockholm: Almqvist and Wiksell. 